\title{
OCORRÊNCIA DO NEMATÓIDE DA CASCA PRETA EM INHAME NO ESTADO DE SÃO PAULO
}

\author{
Ana Ines Lucena Lordello ${ }^{1}$ \\ Ailton Rocha Monteiro ${ }^{2}$ \\ Rubens R. A. Lordello ${ }^{3}$
}

O exame de uma amostra de inhame (Dioscorea alata var. rotundata), procedente do município de Planalto, com lesões necróticas, rachaduras superficiais e grandes manchas pardo escuras sob a casca, levou a identificação do nematóide Scutellonema bradys (Steiner \& Le Hew, 1933) Andrássy, 1958 pela primeira vez no Estado de São Paulo, em 04 de maio de 2005, causando prejuízos à cultura do inhame (Siddiqi, 1972).

Esse nematóide é importante parasito do inhame em várias partes do mundo. No Brasil é problema sério ao seu cultivo nos Estados do Nordeste, onde foi constatada sua presença em 39\% das amostras destinadas à exportação, inviabilizando-as para esse mercado (Freitas, Dantas e Fontes, 1986).

O manejo desse nematóide na cultura do inhame é obtido principalmente pela prevenção da disseminação, com o plantio de túberas sadias em solos não infestados. Outras alternativas citadas na literatura são a rotação, o uso de nematicidas e o tratamento hidrotérmico do material de plantio.

\footnotetext{
'EMBRAPA/IAC, Centro de Pesquisa e Desenvolvimento de Fitossanidade, Área de Nematologia, Cx. P. 28, 13020-902 Campinas, SP. e-mail: analord@iac.sp.gov.br ${ }^{2}$ Dep. de Entomol., Fitopatol. e Zoologia Agrícola, ESALQ/USP, 13418-900 Piracicaba, SP.

${ }^{3}$ Instituto Agronômico de Campinas, Centro de Pesquisa e Desenvolvimento de Fitossanidade, Área de Nematologia, Cx. P. 28, 13020-902 Campinas, SP. E-mail: lordello@iac.sp.gov.br
} 


\title{
Occurrence of dry rot of yams at São Paulo State, in Brazil
}

\begin{abstract}
On a sample of yam tubers (Dioscorea alata var. rotundata) that showed areas with deep cracks and black lesions under the tuber skin, were found a large number of specimens of Scutellonema bradys (Steiner \& Le Hew, 1933) Andrássy, 1958, the agent of dry rot of yams. This is the first occurrence of this nematodes species on yam at Planalto county, at São Paulo State, in Brazil, in May of 2005.

Key words: occurrence, Scutellonema bradys, yam, São Paulo State, Brazil.
\end{abstract}

\section{REFERÊNCIAS BIBLIOGRÁFICAS}

FREITAS, O.M.B.L., M.P. DANTAS \& M.D. Ponte, 1986. Identificação de fitonematóides no Estado de Pernambuco. X Reunião Brasileira de Nematologia, Mossoró, 24-48/02/1986. p. 65 (Resumo).

SIDDIQI, M.R., 1972. Scutellonema bradys. In: C.I.H. Descriptions of plant-parasitic nematodes: Set $1, \mathrm{n}^{\circ}$ 5, Farnham Royal, UK: Commonwealth Agricultural Bureaux, 2p. 